Case Report

\title{
Cake kidney-complete crossed fused ectopia
}

\section{Abstract}

Cake kidney or complete crossed fused renal ectopia refers to complete fusion of both kidneys and remain on the same side of the midline. It is due to failure of normal renal ascent during embryogenesis with fusion of kidneys within the renal pelvis. ${ }^{1,2}$ We present a case of 18years old male with heaviness in right lumbar region and CECT was done which showed complete crossed renal ectopia. ${ }^{3}$

Keywords: Cake kidney, crossed fused, embryogenesi

\author{
Volume 4 Issue I - 2019 \\ Lokesh Rana,' Dinesh Sood,' Pooja Gurnal,' \\ Manjuswamy $\mathrm{HR}^{2}$ \\ 'Department of Radio-diagnosis, DRPGMC, India \\ ${ }^{2}$ Department of Anaesthesia, DRPGMC, India
}

Correspondence: Lokesh Rana, Assistant Proffesor,

Department of Radio-diagnosis, Dr RPGMC, Kangra at Tanda, Himachal Pradesh, India, Email poojalokesh2007@gmail.com

Received: December 12, 2018 | Published: January 28, 2019

\section{Case report}

We present a case of an 18year old male presented with heaviness right lumbar region for 1 year. The NCCT and CECT images shows complete crossed fused renal ectopia on right side with central hyperdensity in the medulla with ureters are on seen draining on same side of UB (Figure 1).
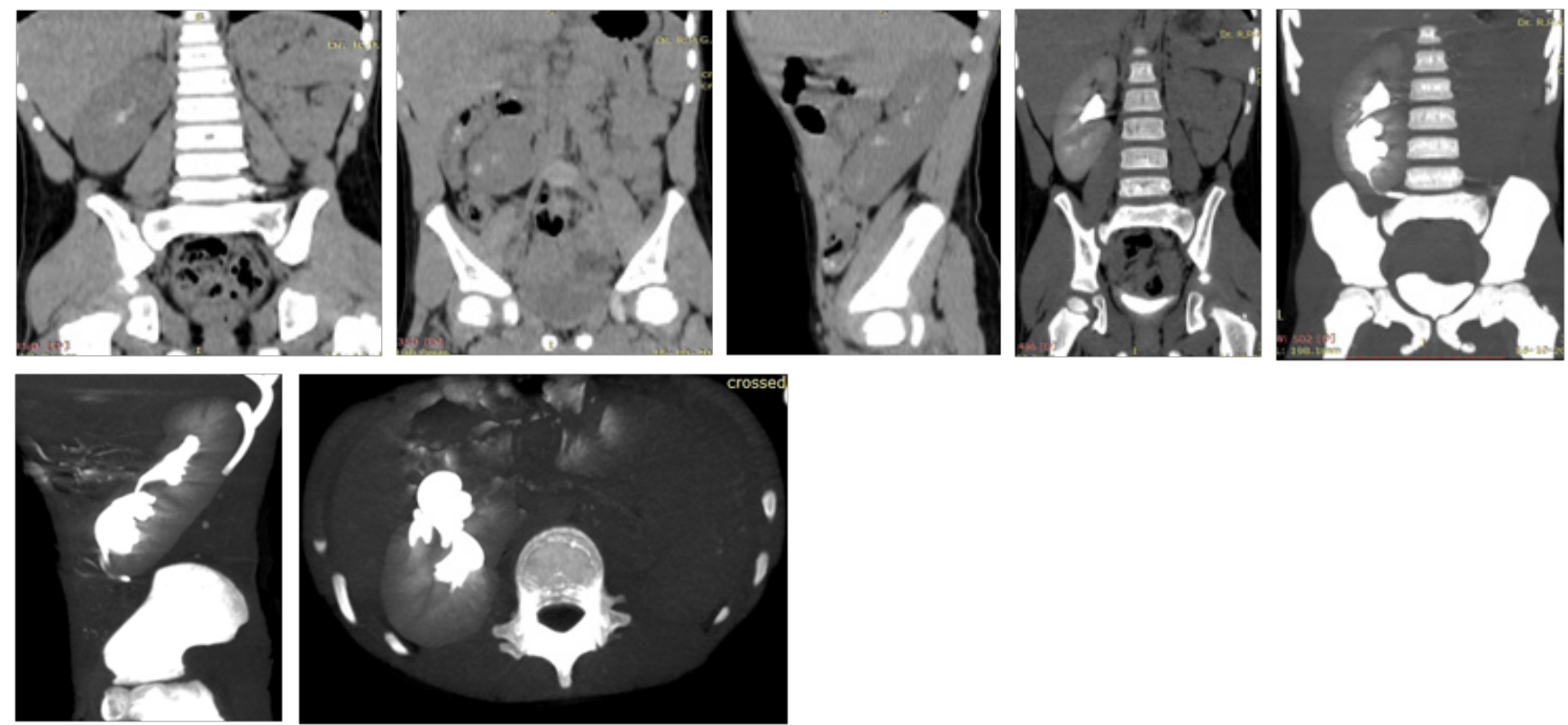

Figure I A 18 year presented with heaviness right lumbar region NCCT and CECT images shows complete crossed fused renal ectopia on right side with central hyperdensity in the medulla with ureters are on seen draining on same side of UB.

\section{Discussion}

Cake kidney or complete crossed fused renal ectopia refers to complete fusion of both kidneys and remain on the same side of the midline. It is due to failure of normal renal ascent during embryogenesis with fusion of kidneys within the renal pelvis. ${ }^{1-4}$

\section{Clinical presentation}

Many a times this entity is asymptomatic or may present with obstruction, urolithiasis, reflux or infection. ${ }^{5}$

\section{Key Imaging diagnostic clues}

i. Abnormal location of the kidney in this case fusion within same side of the midline. ${ }^{1,4,6}$ ii. Types are superior when lies superior to resident kidney, sigmoid when crossed kidney lying inferiorly, unilateral lump and unilateral disc. ${ }^{7}$

\section{Conclusion}

Crossed fused renal ectopia is asymptomatic unless complicated by infection, reflux or urolithiasis. Computed tomography is important in diagnosis, defining its subtype and surgical planning if causing complications.

\section{Acknowledgments}

None. 


\section{Conflicts of interest}

Author declares there is no conflict of interest towards this article.

\section{References}

1. Bhattar R, Maheshwari A, Tomar V, et al. Crossed Fused Ectopic Kidney: A Case Report. Journal of clinical and diagnostic research: J Clin Diagn Res. 2017;11(8):PD11-PD12.

2. Türkvatan A, Ölçer T, Cumhur T. Multidetector CT urography of renal fusion anomalies. Diagn Interv Radiol. 2009;15(2):127-134.

3. Chow LC, Sommer FG. Multidetector CT urography with abdominal compression and three-dimensional reconstruction. Am J Roentgenol. 2001;177(4):849-855.
4. Kawashima A, Vrtiska TJ, LeRoy AJ, et al. CT Urography. Radiographics. 2004;24:S35-S58.

5. Noroozian M, Cohan RH, Caoili EM, et al. Multislice CT urography: state of the art. Br J Radiol. 2004;77:S74-S86.

6. Beer AJ, Dobritz M, Zantl N, et al. Comparison of 16-MDCT and MRI for characterization of kidney lesions. AJR Am J Roentgenol. 2006;186(6):1639-1650.

7. Nikken JJ, Krestin GP. MRI of the kidney: state of the art. Eur Radiol. 2007;17(11):2780-2793. 